\title{
Trends in incidence of childhood cancers in the Czech Republic: population- based analysis of national registries (1994-2014)
}

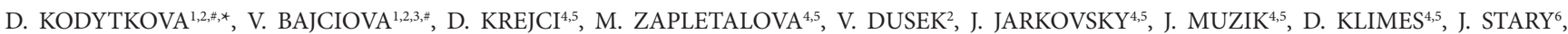 \\ V. SMELHAUS ${ }^{6}$, A. VRZALOVA 6 , I. JANOTOVA ${ }^{6}$, J. STERBA ${ }^{1,2,3}$, L. DUSEK ${ }^{4,5}$ \\ ${ }^{1}$ Department of Pediatric Oncology, University Hospital Brno, Brno, Czech Republic; ${ }^{2}$ Department of Pediatric Oncology, Faculty of Medicine, \\ Masaryk University, Brno, Czech republic; ${ }^{3}$ International Clinical Research Center, St. Anne's University Hospital Brno, Brno, Czech Republic; \\ ${ }^{4}$ Institute of Biostatistics and Analyses, Faculty of Medicine, Masaryk University, Brno, Czech Republic; Institute of Health Information and \\ Statistics of the Czech Republic, Prague, Czech Republic; 'Department of Pediatric Haematology and Oncology, Second Faculty of Medicine, \\ Charles University, Prague, Czech Republic
}

${ }^{*}$ Correspondence: kodytkova.daniela@fnbrno.cz

Received May 17, 2017 / Accepted November 14, 2017

\begin{abstract}
The purpose of this study is to summarize incidence and trends in the pediatric cancer burden in the Czech Republic over the period 1994-2014. The recently established Childhood Cancer Registry was combined with retrospective data from the Czech National Cancer Registry to analyze the annual patterns of incidence and long-term trends of pediatric cancer patients aged 0-14 years diagnosed between 1994 and 2014. Malignancies were classified according to the International Classification of Childhood Cancer. The distribution of incidence was stratified according to gender, age at diagnosis, type of cancer and geographic area. Annual age-standardized rates were adjusted using the world standard population. Changes over time were quantified as the average annual percentage change. This analysis comprised records of 5,605 children diagnosed with cancer within the period 1994-2014, annually 267 records on average; the overall age-standardized average annual incidence rate was 169 cases per million. Boys were affected more frequently than girls: the M/F crude incidence ratio was 1.2:1. The highest incidence rates were observed for ICCC groups I (27.8\%), III (21.8\%), II (12.4\%) and IV (7.8\%); other groups formed $30.2 \%$. There are significant differences in the geographic distribution of incidence between regions. A borderline statistically significant increase $(0.6 \%)$ in the overall average annual percentage change was detected between 1994 and 2014 (95\% CI: 0.01 to 1.12; $\mathrm{p}=0.05)$. This study provides reliable recent information on trends in the incidence of childhood cancers in the Czech Republic.
\end{abstract}

Key words: childhood, cancer, registry, incidence, epidemiology, Czech Republic

In European population, childhood cancers (i.e. those occurring in patients under the age of 20) represent rather rare diseases, accounting for less than $1 \%$ of the overall cancer burden in the general population. Diagnoses of pediatric cancer patients are substantially different from those in the adult population, where carcinomas represent the most frequent type of cancer. Acute lymphoblastic leukemia (32\%), brain tumors (22\%) and malignant lymphomas (12\%) are the most common cancers in children under the age of 15 . There are considerable variations in the incidence of childhood cancers among countries worldwide as well as in Europe. Based on European data from the period 1988-1997, the annual incidence rates range from 131 cases (British Isles) to 160 cases (Scandinavian countries) per million children and slightly increase in time [1].
Despite enormous improvements in survival of pediatric cancer patients in the last decades, cancer still remains the second most common cause of death in children aged under 15 in developed countries [2, 3]. Therefore, reliable information about trends in incidence, prevalence, survival and mortality of childhood cancers is crucial for management, planning and optimization of care for pediatric cancer patients. The international population-based project European Cancer Registry (EUROCARE, with its latest version EUROCARE-5) is the biggest European project quantifying survival data from 74 population-based cancer registries in 29 countries. Most European countries maintain general population-based cancer registries, but only 10 registries specialized in childhood cancers contributed to the EUROCARE survey $[2,4]$. Registries specialized in child- 
hood cancers are of a great value because the manner of grouping and classification of pediatric cancers is different from cancers in the adulthood. Tumors in adults are classified according to the International Classification of Diseases for Oncology (ICD-O-3) [5], which is primarily based on the location of the primary tumor. However, such classification is inadequate for pediatric cancers. For childhood cancers, the International Classification of Childhood Cancer (ICCC) [6] has been widely accepted as the gold standard. It is based on morphology records which classify tumors into 12 main groups. Tumors in children are staged according to a diseasespecific staging system, whereas tumors in adults are classified on the basis of the TNM Classification of Malignant Tumors (TNM) [7,8].

The Czech Childhood Cancer Registry (CCR) is the first pediatric cancer registry established in the Czech Republic, covering the children's population in the long term. CCR objectives are to estimate the real incidence of childhood cancers on the national level, to quantify time-related trends in incidence, to describe geographical differences and, finally, to evaluate population-based survival and mortality rates of childhood cancers.

This is the first report on the incidence of childhood cancers in the Czech Republic and the first report of the national pediatric cancer registry generated since its initiation in 2008. The report combines data from the CCR with data from the general Czech National Cancer Registry (CNCR) and summarizes records on childhood cancer incidence in the period 1994-2014.

\section{Patients and methods}

Patients' data sources. The population-based CNCR is the main source of cancer epidemiology in the Czech Republic, http://www.uzis.cz/registry-nzis/nor [9]. The CNCR was established in 1976 and has been an integral part of the Czech National Cancer Control Program, which had been agreed in December 2003 by the Board of the Czech Society for Oncology (and amended in April 2013). The CNCR contains more than 2,000,000 records on cancer cases from the period 1977-2014, covering $100 \%$ of the Czech population. The CNCR is administered by the Institute of Health Information and Statistics of the Czech Republic (IHIS CR) and is part of the National Health Information System (NHIS), http://www. uzis.cz/en/about-us/information-about-nhis [10]. The registration of cancer cases is mandatory in the Czech Republic. Selected reports on cancer epidemiology are available on the web portal www.svod.cz [11]. In the Czech Republic, cancer care provided to children and adolescents is professionally guaranteed by the Pediatric Section of the Czech Oncological Society, and pediatric patients with solid tumors are centralized in two comprehensive pediatric oncology centers (the Department of Pediatric Hematology and Oncology at University Hospital Motol in Prague and the Department of Pediatric Oncology at University Hospital Brno). Apart from the two major centers, children with leukemia are treated in six regional hospitals, which improve their access to cancer care. In 2008, representatives of the Pediatric Section of the Czech Oncological Society decided to develop a national database of pediatric cancers in the Czech Republic, the newly established CCR. This database contains all necessary items for reports required by the CNCR; additionally, its structure is extended in order to satisfy the particularities of pediatric cancers, including the special classification system (ICCC-3) as well as specific treatment protocols. The mandatory minimum set of parameters includes morphological and topographical coding of histological or cytological examination, the validity of which is strictly checked against the ICD-O-3 classification. Population data from 1994 to 2007 were managed retrospectively. Since 2008, data sets have been collected prospectively in the two above-mentioned centers. The database contains a total of 1,790 records from the prospectively-collected period of 2008-2014. Records on pediatric cancer patients diagnosed before 2008 were retrospectively exported from the general CNCR database and entered to the CCR. Demographic population data were obtained from the Czech Statistical Office (CSO); these data have also been published at the CSO website (www.czso.cz) [12].

Methods. Population-based annual means for the given age classes were used as the base for the calculation of incidence rates in the period 1994-2014 (Table 1). Age-standardized incidence rates - ASR (W) - were directly estimated for the age groups 0-14 years using the weights of the world standard population [13]. Confidence intervals (95\% CI) were calculated for all point statistical estimates. Microscopy-verified cases (in \%) are defined as cases whose diagnosis was determined by cytology, histological examination of the metastasis or of the primary tumor. The comparison of the incidence rate ASR (W) between specific region and the Czech Republic was performed by the MantelHaenszel test. For the calculation of ASR (W) in each year, showing the trend, demographic data from particular years was used. Changes over time were computed on the average annual percentage change (AAPC), which was estimated using the formula: $100\left(e^{\beta}-1\right)$, where $B$ is the slope calculated from a linear regression of $\log$ ASR (W) in a calendar year [14]. Statistical analyses and tests were performed using the SPSS software (version 22), Statistica (version 12), Joinpoint regression program (version 4.2.0.2).

\section{Results}

Demographic data. Demographic data CSO (1994-2014) documents that the entire population of the Czech Republic consisted of 10,346,334 inhabitants on average. The average childhood population (0-14 years) consisted of $1,634,580$ children, which represents $16 \%$ of the overall annual average population with a male/female ratio of 1.1:1. Age groups were divided into five-year periods by gender ( $0-4$ years: 
266,591 boys, 252,882 girls; $5-9$ years: 275,334 boys, 261,287 girls; $10-14$ years: 296,594 boys, 281,893 girls).

Incidence data. In the period 1994-2014, the total number of 5,605 pediatric cancers in children aged $0-14$ years were registered in the CNCR and in the CCR; the mean annual incidence was 267 cases. Table 1 summarizes the numbers of cases and incidence rates in all groups and subgroups of diagnoses according to the ICCC. The age-standardized average annual incidence rate was estimated as 169 per million (95\% CI: 164.9-173.9). The overall male/female ratio was 1.2:1 according to the ASR (W). In total, $93.4 \%$ of cases were microscopically verified.

All types of malignancies were grouped into 12 diagnostic categories according to the ICCC-3 [7] (Figure 1). The summary revealed that groups I-IV were the most common cancer types. The most commonly diagnosed ICCC subgroups were: lymphoid leukemias (21.6\%), astrocytomas (9.1\%), neuroblastomas and ganglioneuroblastomas (7.6\%), Hodgkin lymphomas (5.0\%), nephroblastomas and other non-epithelial renal tumors (4.8\%) (Table 1).

Incidence by age. The highest incidence rates for all pediatric cancers combined were found in the under-fives. This pattern varied markedly according to the cancer type (Figure 2).

The age-specific profile of cancer types is shown in Figure 3. The profile documents a decreasing proportion of tumors of embryonic origin (neuroblastoma and other peripheral nervous cell tumors, retinoblastoma, renal tumors and hepatic tumors) with the increasing age of children. Neuroblastoma was the most common cancer type (31\%) in infants (age $<1$ year), whereas children aged more than 1 year suffered most frequently from leukemias; this trend culminated in the category of 3-year-old children.

Incidence by gender. There was a slight predominance of boys during the examined period $(\mathrm{p}<0.05)$. Boys were more frequently affected by all common cancer types than girls (Figure 4).

Regional incidence. The Czech Republic is composed of 14 regions. Each individual region keeps its own epidemiological reporting in the CNCR and validates records collected from the pediatric cancer care centers. We analyzed the incidence in each region and tried to find differences in the incidence of childhood cancers. Increased incidence rates of childhood cancers were identified in the Capital of Prague, the neighboring Central Bohemian Region, the South Moravian Region and the Vysocina Region (Figure 5). On the contrary, the lowest ASR (W) was found in the Karlovy Vary Region, the Pardubice Region and in the Hradec Kralove Region. In comparison with the incidence rate of the entire Czech Republic, a statistically significant difference was confirmed only in two cases: the Hradec Kralove Region ( $\mathrm{p}=0.01$ ) and the Pardubice Region ( $\mathrm{p}=0.04$, Mantel-Haenszel test).

Trends in incidence. A long-term increasing trend in the incidence of all childhood cancers combined was revealed

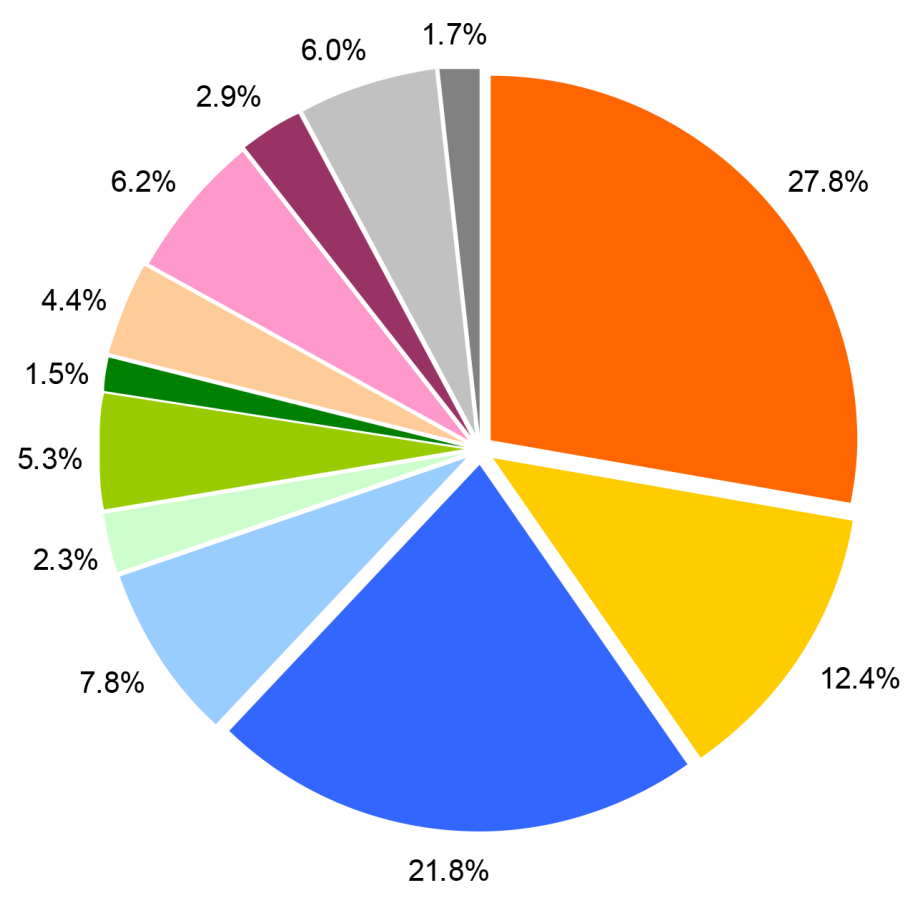

Leukemias, myeloproliferative diseases, and myelodysplastic diseases

II Lymphomas and reticuloendothelial neoplasms

III CNS and miscellaneous intracranial III and intraspinal neoplasms

IV Neuroblastoma and other peripheral IV nervous cell tumors

V Retinoblastoma

VI Renal tumors

VII Hepatic tumors

VIII Malignant bone tumors

\begin{tabular}{ll}
\hline IX & $\begin{array}{l}\text { Soft tissue and other extraosseous } \\
\text { sarcomas }\end{array}$ \\
\hline $\mathbf{X} \quad \begin{array}{l}\text { Germ cell tumors, trophoblastic tumors, } \\
\text { and neoplasms of gonads }\end{array}$ \\
\hline $\mathbf{X I} \quad \begin{array}{l}\text { Other malignant epithelial neoplasms } \\
\text { and malignant melanomas }\end{array}$ \\
\hline $\mathbf{X I I}$ & $\begin{array}{l}\text { Other and unspecified malignant } \\
\text { neoplasms }\end{array}$
\end{tabular}

Figure 1. Relative rate (\%) of 12 diagnostic groups according to the ICCC in children aged 0-14 years (the Czech Republic, 1994-2014) 


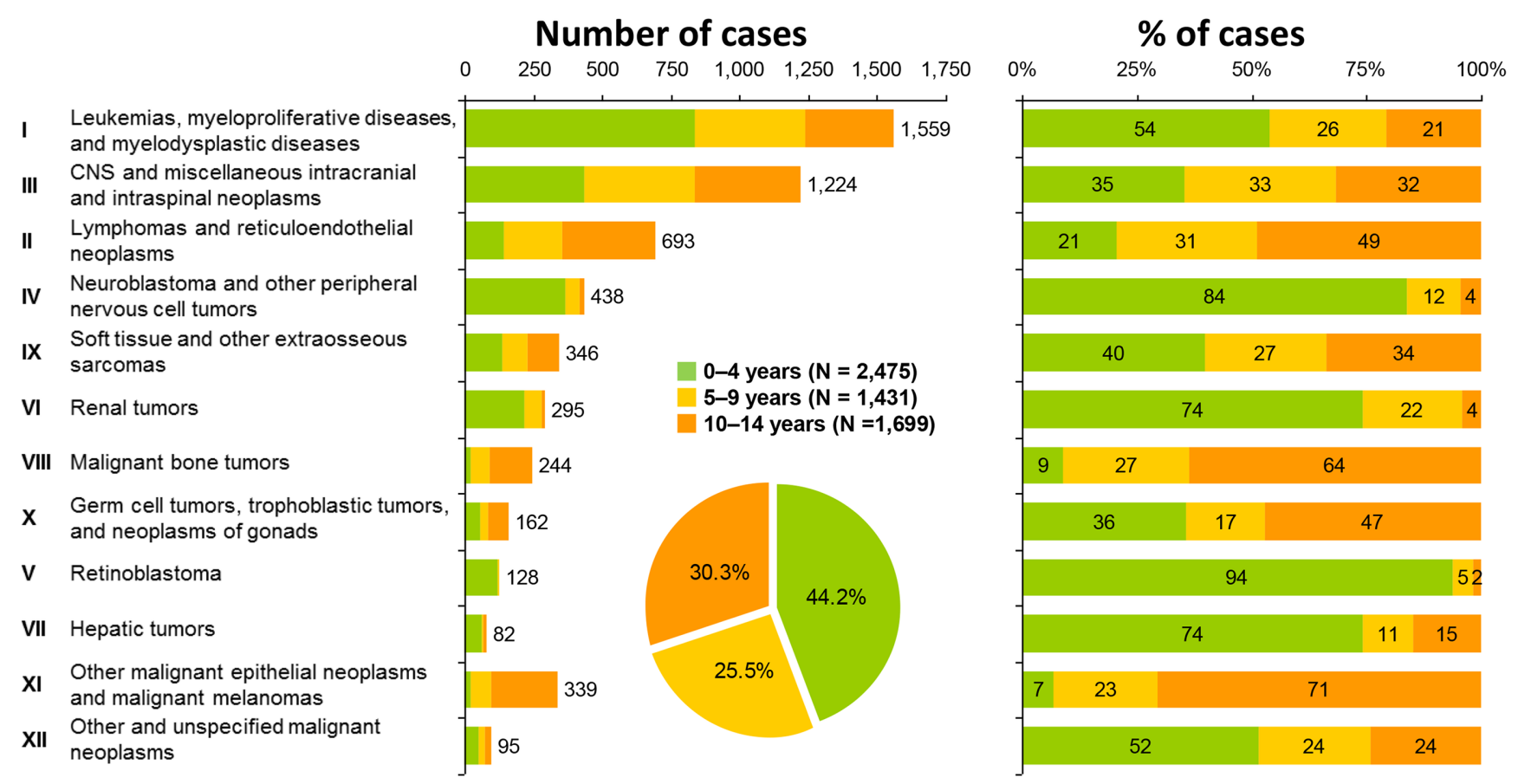

Figure 2. Number and \% of cases according to the patient's age and cancer type (the Czech Republic, 1994-2014)

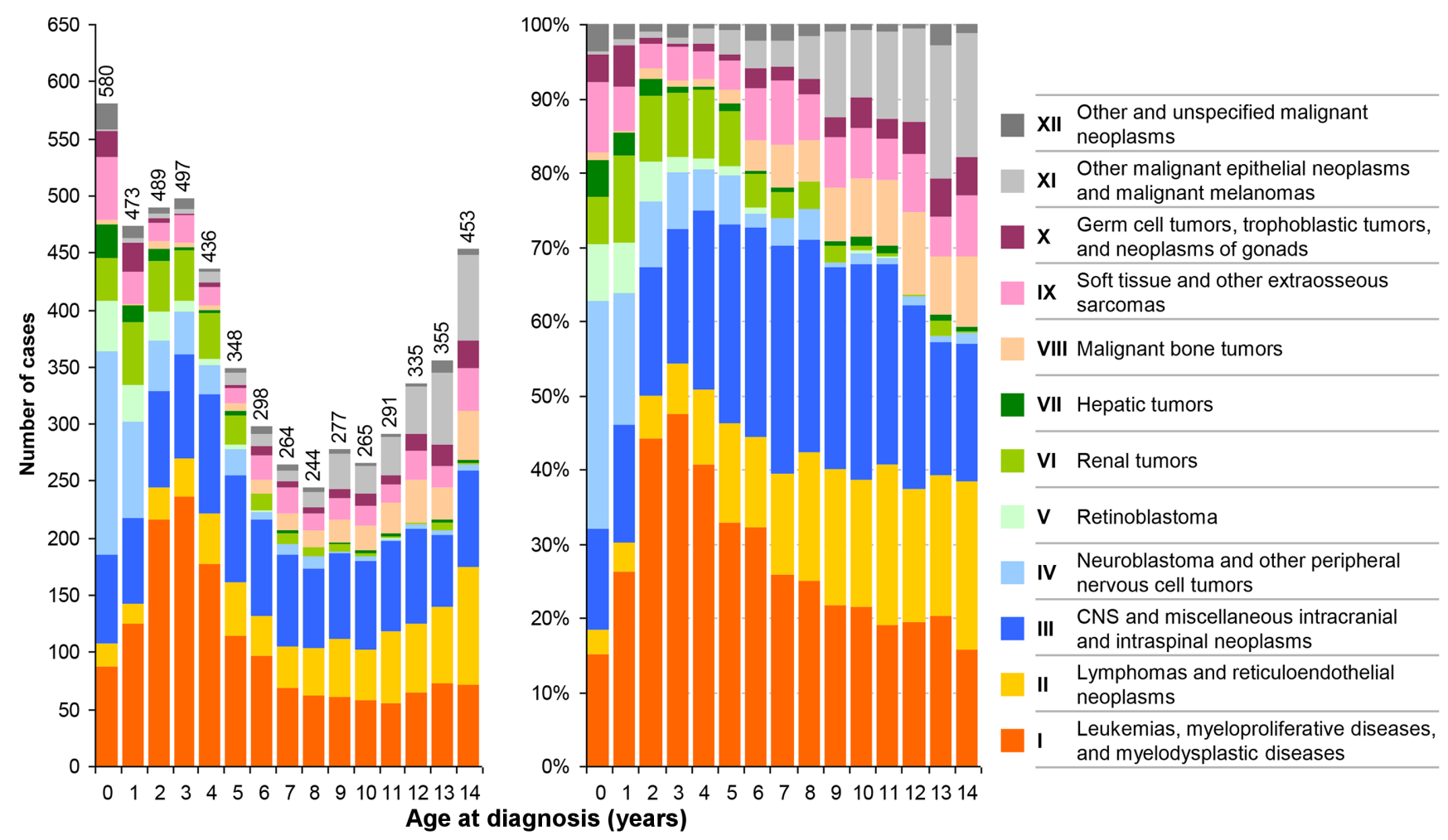

Figure 3. Cases of childhood cancer according to the diagnostic group and age at the time of diagnosis (the Czech Republic, 1994-2014) 


\section{$\operatorname{ASR}(\mathrm{W})$ \\ Age standardization per $1,000,000$ children}

\section{$\%$ of cases}

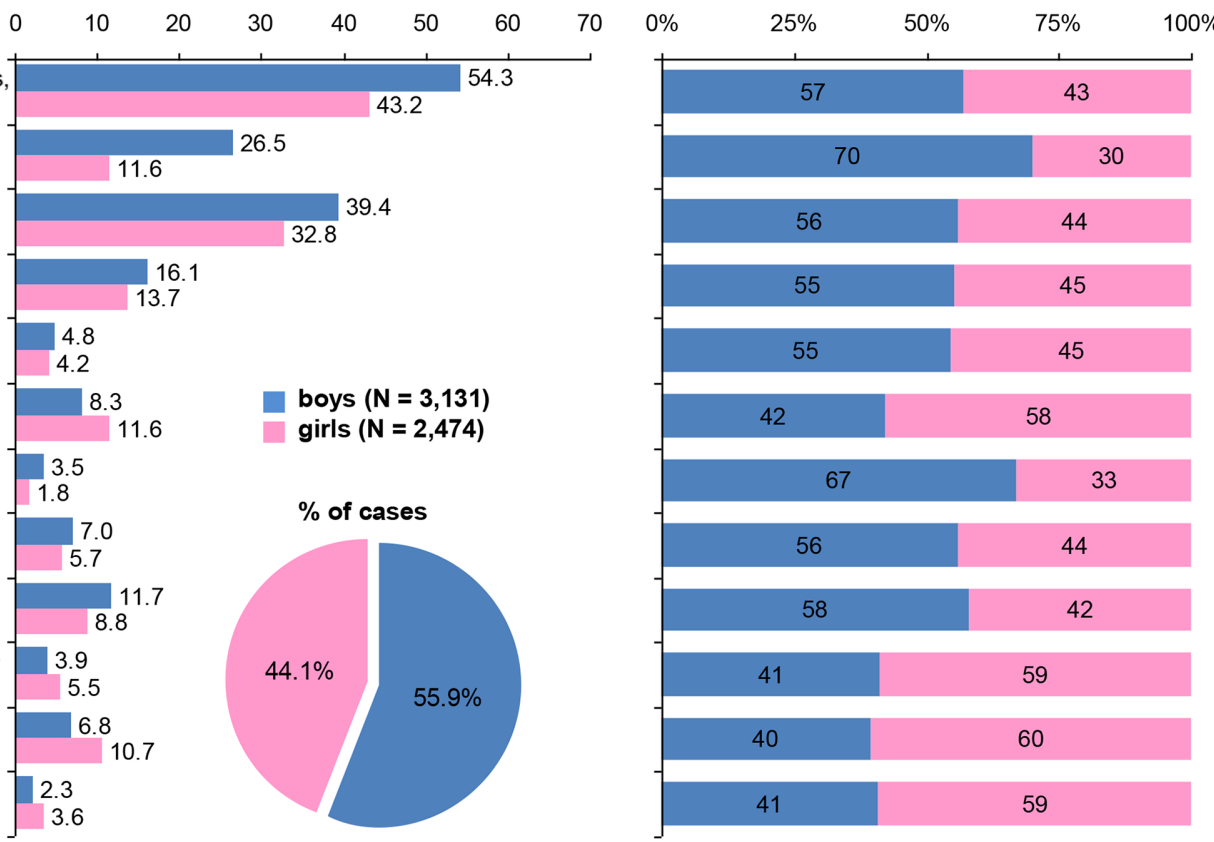

Figure 4. ASR (W) per 1,000,000 children and \% of cases according to gender and type of cancer (the Czech Republic, 1994-2014)

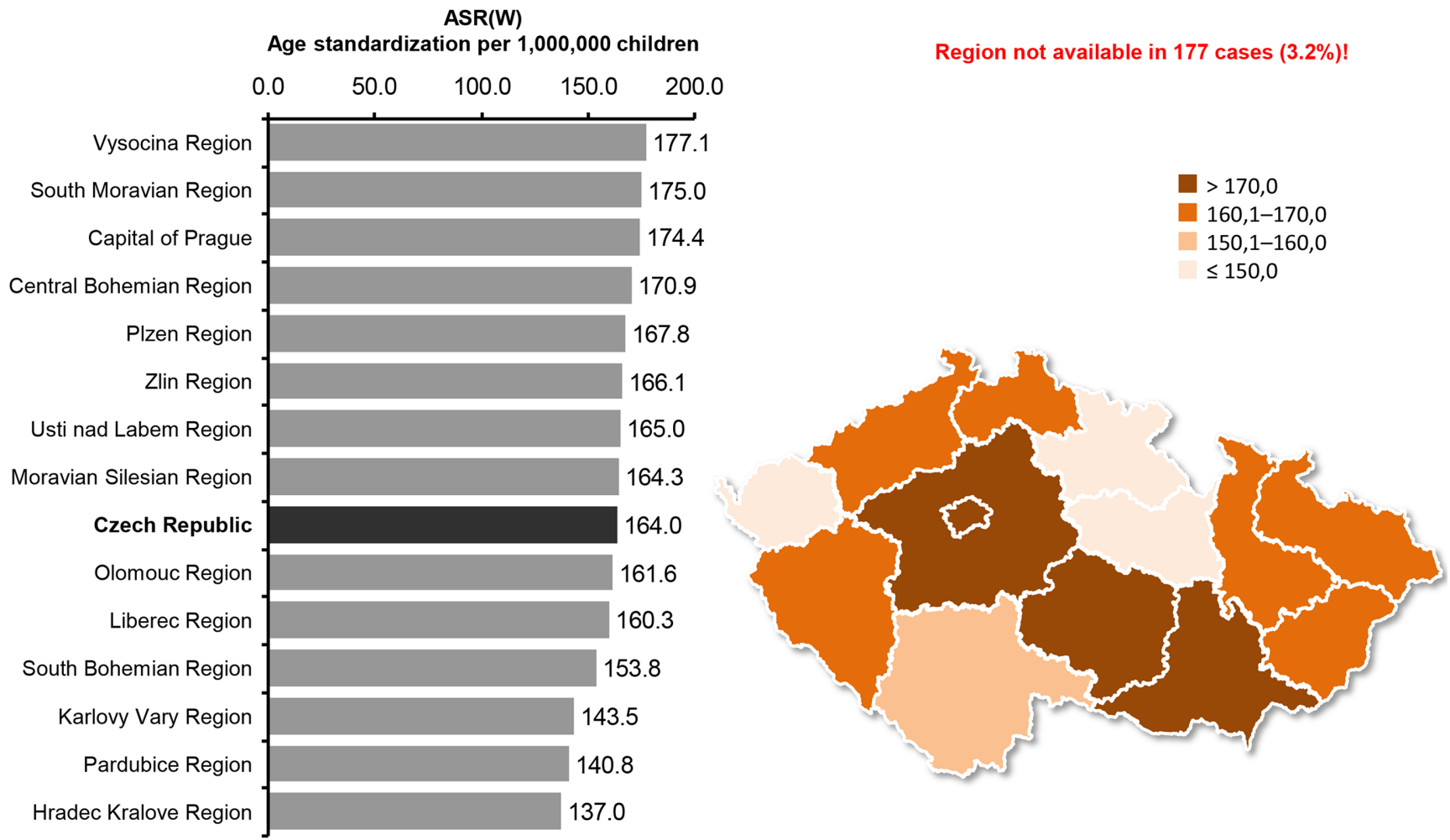

Figure 5. Regional distribution of childhood cancer incidence expressed as ASR (W) per 1,000,000 children (the Czech Republic, 1994-2014) 
Table 1. Number of cases and incidence rates by gender in the childhood population aged 0-14 years (the Czech Republic, 1994-2014).

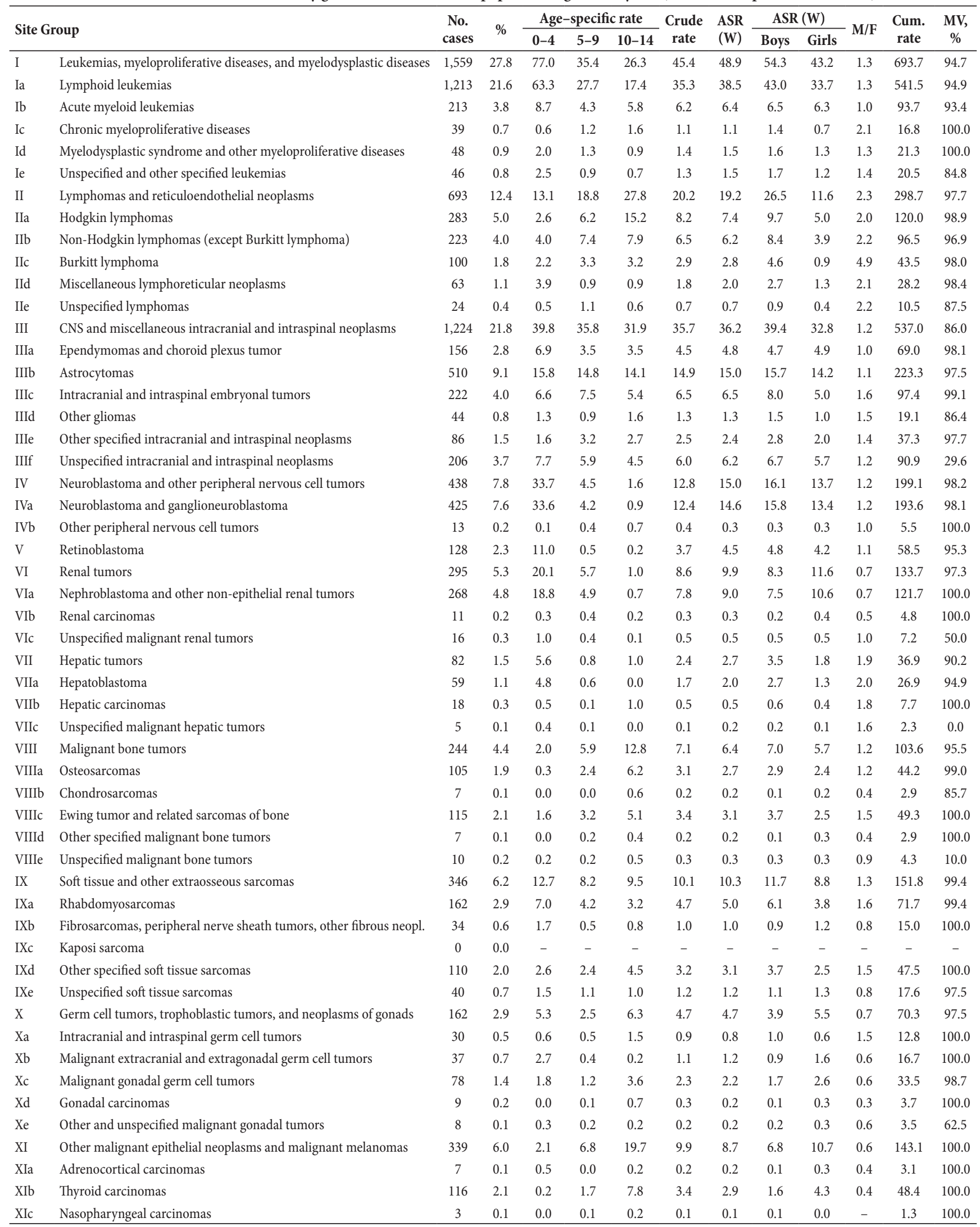


Table 1. (continued)

\begin{tabular}{|c|c|c|c|c|c|c|c|c|c|c|c|c|c|}
\hline \multirow{2}{*}{\multicolumn{2}{|c|}{ Site Group }} & \multirow{3}{*}{$\begin{array}{c}\begin{array}{c}\text { No. } \\
\text { cases }\end{array} \\
85\end{array}$} & \multirow{3}{*}{$\begin{array}{l}\% \\
1.5\end{array}$} & \multicolumn{3}{|c|}{ Age-specific rate } & \multirow{3}{*}{$\begin{array}{c}\text { Crude } \\
\text { rate }\end{array}$} & \multirow{3}{*}{$\begin{array}{c}\begin{array}{c}\text { ASR } \\
(W)\end{array} \\
2.2\end{array}$} & \multicolumn{2}{|c|}{$\operatorname{ASR}(\mathrm{W})$} & \multirow{3}{*}{$\begin{array}{c}\mathbf{M} / \mathbf{F} \\
1.2\end{array}$} & \multirow{3}{*}{$\begin{array}{c}\begin{array}{c}\text { Cum. } \\
\text { rate }\end{array} \\
36.0\end{array}$} & \multirow{3}{*}{$\begin{array}{c}\begin{array}{c}\text { MV, } \\
\%\end{array} \\
100.0\end{array}$} \\
\hline & & & & \multirow{2}{*}{$\begin{array}{c}\mathbf{0 - 4} \\
0.8\end{array}$} & \multirow{2}{*}{$\begin{array}{c}5-9 \\
1.8\end{array}$} & \multirow{2}{*}{$\begin{array}{c}\mathbf{1 0 - 1 4} \\
4.6\end{array}$} & & & \multirow{2}{*}{$\begin{array}{c}\text { Boys } \\
2.5\end{array}$} & \multirow{2}{*}{$\begin{array}{c}\text { Girls } \\
2.0\end{array}$} & & & \\
\hline XId & Malignant melanomas & & & & & & & & & & & & \\
\hline XIe & Skin carcinomas & 53 & 0.9 & 0.2 & 1.5 & 2.8 & 1.5 & 1.4 & 0.9 & 1.9 & 0.4 & 22.5 & 100.0 \\
\hline XIf & Other and unspecified carcinomas & 75 & 1.3 & 0.5 & 1.8 & 4.1 & 2.2 & 1.9 & 1.7 & 2.3 & 0.7 & 31.7 & 100.0 \\
\hline XII & Other and unspecified malignant neoplasms & 95 & 1.7 & 4.5 & 2.0 & 1.9 & 2.8 & 2.9 & 2.3 & 3.6 & 0.6 & 42.1 & 44.2 \\
\hline XIIa & Other specified malignant tumors & 12 & 0.2 & 0.6 & 0.3 & 0.2 & 0.3 & 0.4 & 0.2 & 0.6 & 0.3 & 5.3 & 100.0 \\
\hline \multirow[t]{2}{*}{ XIIb } & Other unspecified malignant tumors & 83 & 1.5 & 3.9 & 1.8 & 1.6 & 2.4 & 2.6 & 2.1 & 3.0 & 0.7 & 36.8 & 36.1 \\
\hline & All cancers & 5,605 & 100.0 & 226.9 & 127.0 & 139.9 & 163.3 & 169.4 & 184.6 & 153.3 & 1.2 & $2,468.6$ & 93.4 \\
\hline
\end{tabular}

$\%=\%$ of all cancers; Age-specific rate (per million); Crude rate (per million); ASR = age-standardized rate (all rates are expressed as per million, standard world population); $\mathrm{M} / \mathrm{F}=$ male/female ratio; $\mathrm{Cum}$. rate = cumulative rate (per million); $\mathrm{MV}=$ microscopic verification.

in the examined period 1994-2014: the age-standardized incidence increased from 144.2 in 1994 to 154.1 in 2014. Correspondingly, a borderline significant increase in the overall AAPC was observed (an increment of $0.6 \%$ between 1994 and 2014, 95\% CI: 0.01 to 1.12; $\mathrm{p}=0.05$ ). The growing trend of burden is also observable mostly in the analysis stratified according to cancer types (Figure 6 and 7). The most significant incidence increase was detected in the ICCC group XI (Other malignant epithelial neoplasms and malignant melanomas, $+5.0 \%, \mathrm{p}<0.01$; mainly due to the increase subgroups malignant melanoma, $+11.0 \%, p<0.01$ ), group IX (Soft tissue and other extraosseous sarcomas, $+2.6 \%, \mathrm{p}<0.05$ ) and group III (CNS and miscellaneous intracranial and intraspinal neoplasms, $+1.4 \%, \mathrm{p}<0.05)$. On the other hand, group II (Lymphomas and reticuloendothelial neoplasms) revealed a decreasing incidence trend over the examined period $(-1.8 \%, \mathrm{p}<0.05)$. In the population of pediatric cancer patients, there was an increase in the proportion of age category $0-4$ years from $41.8 \%$ in the first period (1994$2004)$ to $46.9 \%$ in the second period (2005-2014), and a slight decrease in the proportion of age categories 5-9 years and $10-14$ years.

\section{Discussion}

In Europe, the incidence of childhood cancers in 2012 was estimated as 139 cases per million [15]. However, the incidence and mortality of childhood cancers significantly differ worldwide [16-19]. The annual world age-standardized incidence of childhood cancers in patients aged less than 15 years was approximately 164 per million in Germany (20032012) [20], 158 per million in Austria (2003-2011) [21] and 153 per million in the United Kingdom (2011-2013) [22].

Our analysis indicates that the incidence of childhood cancers in the Czech Republic is slightly higher than the incidence in other European countries; ASR (W) in the Czech Republic was 169 cases per million children under the age of 15 in the period 1994-2014 (95\% CI: 164.9-173.9). Childhood cancers (i.e. those occurring in patients under the age of 15) represent rather rare diseases, accounting for less than $1 \%$ of the overall cancer burden in the Czech Republic.
The most common cancers in children vary significantly by age $[16,17]$. In pediatric oncology, two distinct age incidence peaks can be distinguished: the first one is located in the age class $0-5$ years, whereas the second one occurs at the age of puberty and adolescence. Indeed, our data have confirmed two age peaks in the incidence of childhood cancers.

In general, boys are affected by cancer more frequently than girls worldwide. Our data have confirmed the male predominance in most cancer types: the male/female incidence ratio was 1.2:1. Girls were affected more frequently only in several diagnostic groups: renal tumors, germ cell tumors, trophoblastic tumors and neoplasms of gonads, other malignant epithelial neoplasms, other and unspecified malignant neoplasms. In comparison to countries neighboring with the Czech Republic, Germany reports a similar predominance in boys (male:female 1.2), while the Austrian population reveals similar incidence rates in both sexes $[20,21]$.

Over the last few decades, there has been a slightly increasing trend in the annual incidence rate of pediatric cancers worldwide. In the United States, the incidence rate was increasing by $0.6 \%$ each year on average in the period 1975-2010 [23]. In Europe, the annual incidence of childhood cancers increased by $1.1 \%$ on average in the period 1978-1997; the increase ranged from $0.6 \%$ for leukemias to $1.8 \%$ for soft-tissue sarcomas [24]. Recent Austrian data documented a $0.7 \%$ increase in the annual cancer incidence rate among children in the period 1994-2011, especially due to non-malignant CNS tumors and Non-Hodgkin lymphomas in girls (average increase by $1.4 \%$ each year) [21]. In the Czech Republic, an overall AAPC of $0.6 \%$ was proved as a borderline significant increase in the period 1994-2014 (95\% CI: 0.01 to 1.12 ; $\mathrm{p}=0.05$ ).

Based on German incidence reports from the period 2003-2012, the most common cancer types among under 15 -year-olds in Germany were ICCC group I (leukemias, $33.8 \%$ ), group III (tumors of the central nervous system, $24.0 \%$ ), group II (lymphomas, 11.1\%) and group IV (neuroblastomas, $7.0 \%$ ) [20]. Similar relative incidence profile occurred in the Czech Republic: group I (27.8\%) followed by group III (21.8\%), group II (12.4\%) and group IV (7.8\%). Similar incidence trends are reported from other world 


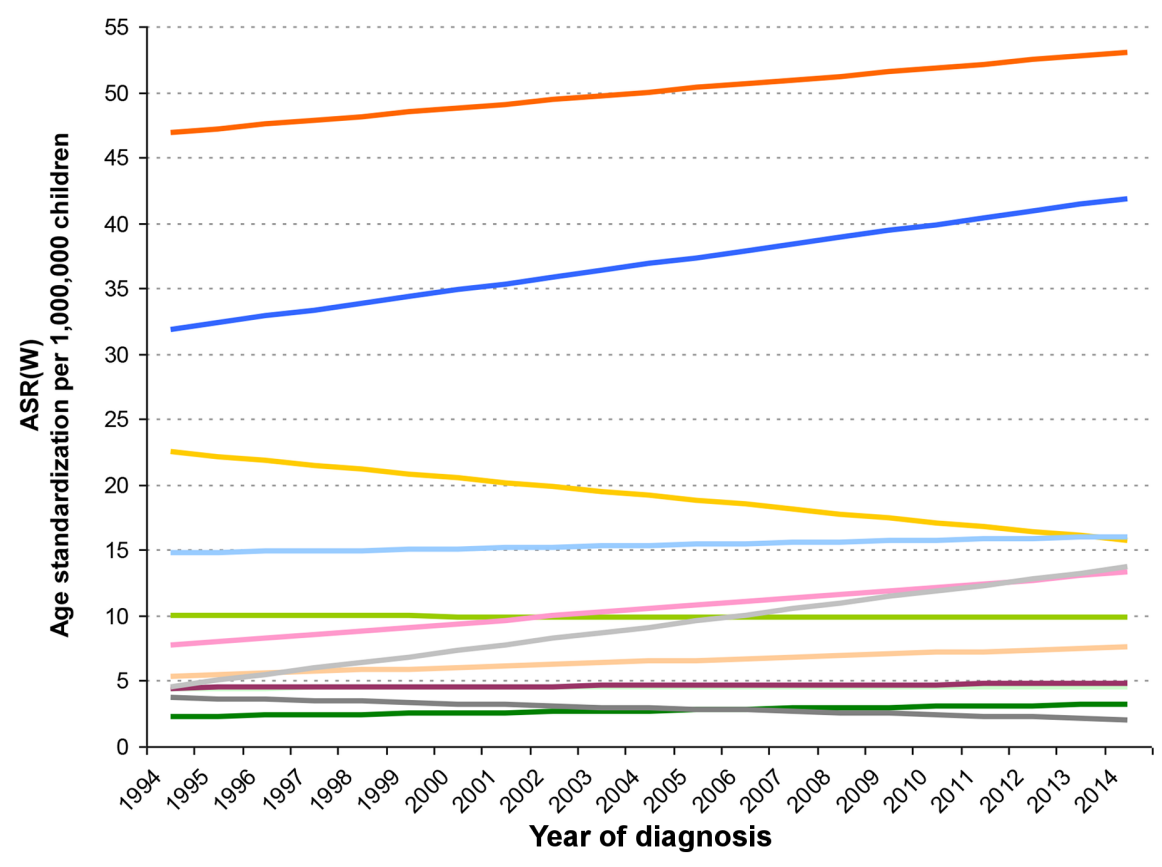

Leukemias, myeloproliferative diseases, and myelodysplastic diseases

II Lymphomas and reticuloendothelial neoplasms

III CNS and miscellaneous intracraniall and intraspinal neoplasms

IV Neuroblastoma and other peripheral

IV nervous cell tumors

v Retinoblastoma

VI Renal tumors

VII Hepatic tumors

VIII Malignant bone tumors

IX Soft tissue and other extra osseous

IX sarcomas

X Germ cell tumors, trophoblastic tumors,

$X$ and neoplasms of gonads

Other malignant epithelial neoplasms

$X \mathbf{I}$ and malignant melanomas

XII Other and unspecified malignant neoplasms

Figure 6. Trends in cancer incidence within the main ICCC groups; the lines represent linear fitted trends (the Czech Republic, 1994-2014)

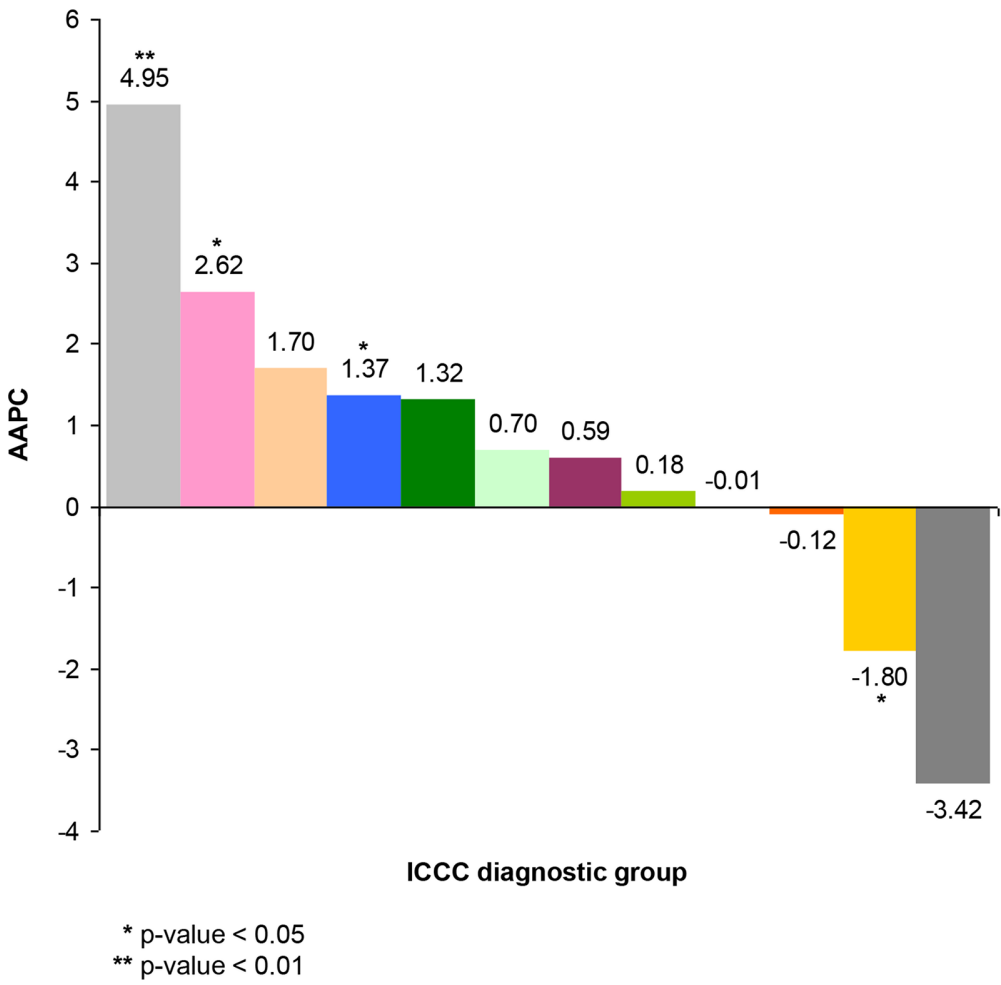

XI Other malignant epithelial neoplasms and malignant melanomas

Soft tissue and other extraosseous

X sarcomas

VIII Malignant bone tumors

III CNS and miscellaneous intracrania and intraspinal neoplasms

VII Hepatic tumors

V Retinoblastoma

X Germ cell tumors, trophoblastic tumors, and neoplasms of gonads

VI Renal tumors

Neuroblastoma and other peripheral

nervous cell tumors

Leukemias, myeloproliferative diseases, and myelodysplastic diseases

II Lymphomas and reticuloendothelial neoplasms

XII Other and unspecified malignant XII neoplasms

Figure 7. Average annual percentage change of cancer incidence by diagnostic groups in children (the Czech Republic, 1994-2014) 
regions, but incidence rates of the main cancer types may vary among countries $[16,18,19]$.

Regional analyses of the incidence of childhood cancers revealed an asymmetric distribution among geographic regions. The differences in the reported records on childhood cancers appear to correlate with the catchment area of specialized high-volume pediatric centers in the Capital of Prague and in the city of Brno. The highest incidence of childhood cancers was reported in regions neighboring with these infrastructure centers (Figure 5). However, pediatric care (both curative and preventive) is very well organized in the Czech Republic. It is easily accessible for patients and parents, so that considerable geographic differences among regions in the density of health care providers do not seem to contribute significantly to the regional distribution of childhood cancers. The reasons for this regional variability in childhood cancer incidence have not yet been fully elucidated.

This is the first fully representative and validated report on childhood cancer incidence in the Czech Republic in the age group 0-14 years which is based on the validated data from population-based registries: the Childhood Cancer Registry and the Czech National Cancer Registry. The analysis of the period 1994-2014 revealed a long-term increasing trend in the incidence rate of most childhood cancers, which corresponds to the results reported by other European countries. It is necessary to develop follow-up work on the mortality and survival rates of pediatric patients, which would yield direct results on the success of the treatment.

Acknowledgements: This work was supported by project No. LQ1605 from the National Program of Sustainability II (MEYS CR).

\section{References}

[1] STILLER CA, MARCOS-GRAGERA R, ARDANAZ E, PANNELLI F, ALMAR MARQUES E et al. Geographical patterns of childhood cancer incidence in Europe, 1988-1997. Report from the automated childhood cancer information system project. Eur J Cancer 2006; 42: 1952-1960. https://doi. org/10.1016/j.ejca.2006.05.017

[2] GATTA G, BOTTA L, ROSSI S, AARELEID T, BIELSKALASOTA $\mathrm{M}$ et al. Childhood cancer survival in Europe 1999-2007: results of EUROCARE-5 a population-based study. Lancet Oncol 2014; 15: 35-47. https://doi.org/10.1016/ S1470-2045(13)70548-5

[3] SIEGEL RL, MILLER KD, JEMAL A. Cancer statistics, 2015. CA Cancer J Clin 2015; 65: 5-29. https://doi.org/10.3322/ caac. 21254

[4] MAGNANI C, GATTA G, CORAZZIARI I, KRAMAROVA E, PASTORE G et al. Childhood malignancies in the EUROCARE study: the database and the methods of survival analysis. Eur J Cancer 2001; 37: 678-686.

[5] FRITZ A, PERCY C, JACK A, SHANMUGARATNAM K, SOBIN L et al. (Eds.). International Classification of Diseases for Oncology, 3rd edition, 1st revision. Geneva, World Health Organization 2013, p 242. ISBN 978-92-4-154849-6.
[6] KRAMAROVA E, STILLER CA. The international classification of childhood cancer. Int J Cancer 1996; 68: $\quad 759-765 . \quad$ https://doi.org/10.1002/(SICI)10970215(19961211)68:6<759::AID-IJC12>3.0.CO;2-W

[7] GUPTA S, AITKEN JF, BARTELS U, BRIERLEY J, DOLENDO $M$ et al. Pediatric cancer stage in population-based cancer registries: the Toronto consensus principles and guidelines. Lancet Oncol 2016; 17: e163-e172. https://doi. org/10.1016/S1470-2045(15)00539-2

[8] SOBIN LH, GOSPODAROWICZ MK, WITTEKIND C. (Eds.). TNM classification of malignant tumors, 7th Edition. Wiley-Blackwell, Chichester 2009, p 332. ISBN 978-1-44433241-4.

[9] [Institute of Health Information and Statistics of the Czech Republic (IHIS). National Health Information System (NHIS). Czech National Cancer Registry (CNCR)]. http:// www.uzis.cz/registry-nzis/nor. Accessed January 1, 2017.

[10] Institute of Health Information and Statistics of the Czech Republic (IHIS), National Health Information System (NHIS). http://www.uzis.cz/en/about-us/informationabout-nhis. Accessed January 1, 2017.

[11] DUSEK L, MUZIK J, KUBASEK M, KOPTIKOVA J, ZALOUDIK J et al. Epidemiology of malignant tumors in the Czech Republic. Masaryk University, Brno, 2005. http:// www.svod.cz. ISSN 1802-8861.

[12] Czech Statistical Office. Czech Demographic Handbook 2015. https://www.czso.cz/csu/czso/czech-demographichandbook - 2015. Accessed January 1, 2017.

[13] DOLL R, PAYNE P, WATERHOUSE JAH. (Eds.). Cancer Incidence in Five Continents, A Technical Report. Berlin, Heidelberg: Springer Berlin Heidelberg, 1966. ISBN 978-3540-03475-9.

[14] BOYLE P, PARKIN DM. Cancer registration: principles and methods. Statistical methods for registries. IARC Sci Publ 1991; 95: 126-158.

[15] FERLAY J, SOERJOMATARAM I, ERVIK M, DIKSHIT R, ESER S et al. GLOBOCAN 2012: Cancer Incidence and Mortality Worldwide. IARC 2018. http://globocan.iarc.fr. Accessed January 1, 2017.

[16] WARD E, DESANTIS C, ROBBINS A, KOHLER B, JEMAL A. Childhood and adolescent cancer statistics, 2014. CA Cancer J Clin 2014; 64: 83-103.

[17] BAO PP, LI K, WU CX, HUANG ZZ, WANG CF et al. Recent incidences and trends of childhood malignant solid tumors in Shanghai, 2002-2010. Zhonghua Er Ke Za Zhi 2013; 51: 288-294.

[18] PARK HJ, MOON EK, YOON JY, OH CM, JUNG KW et al. Incidence and Survival of Childhood Cancer in Korea. Cancer Res Treat 2016; 48: 869-882. https://doi.org/10.4143/ crt.2015.290

[19] FAJARDO-GUTIERREZ A, JUAREZ-OCANA S, GONZALES-MIRANDA G, PALMA-PADILLA V, CARREONCRUZ $\mathrm{R}$ et al. Incidence of cancer in children residing in ten jurisdictions of the Mexican Republic: importance of the Cancer registry (a population-based study). BMC Cancer 2007; 7: 68. https://doi.org/10.1186/1471-2407-7-68 
[20] KAATSCH P, SPIX C. German Childhood Cancer Registry - Report 2012 (1980-2012). Institute of Medical Biostatistics, Epidemiology and Informatics (IMBEI) at the University Medical Center of the Johannes Gutenberg University. Mainz, 2013, pp. 117.

[21] KARIM-KOS HE, HACKL M, MANN G, URBAN C, WOEHRER A et al. Trends in incidence, survival and mortality of childhood and adolescent cancer in Austria, 1994-2011. Cancer Epidemiol 2016; 42: 72-81. https://doi. org/10.1016/j.canep.2016.03.015

[22] Childrens cancer statistics. Cancer Research UK. http:// www.cancerresearchuk.org/health-professional/cancer-statistics/childrens-cancers. Accessed January 1, 2017.
[23] HOWLADER N, NOONE AM, KRAPCHO M, GARSHELL J, NEYMAN N et al. (Eds.). SEER Cancer Statistics Review, 1975-2010. National Cancer Institute, Bethesda, MD, https://seer.cancer.gov/csr/1975_2010/, based on November 2012 SEER data submission, posted to the SEER web site, 2013.

[24] KAATSCH P, STELIAROVA-FOUCHER E, CROCETTI E, MAGNANI C, SPIX C et al. Time trends of cancer incidence in European children (1978-1997): report from the Automated Childhood Cancer Information System project. Eur J Cancer 2006; 42: 1961-1971. https://doi.org/10.1016/j. ejca.2006.05.014 